При подземной прокладке трубопроводов в осложненных условиях происходит неизбежное разрушение уплотненного массива грунта, что приводит к изменению его механических и теплофизических свойств. Как следствие, фактические режимы работы трубопроводов отличаются от проектных.

При проектировании трубопровода важно правильно определить расчетное значение коэффициента теплопроводности грунта. Теплофизические и механические свойства грунтов обратной засыпки не только отличаются от первоначальных, но и продолжают изменяться на протяжении эксплуатации трубопровода. Изменение влажности вмещающего грунта также влияет на теплообмен системы «труба грунт». Чем ближе к северным регионам находится зона заложения трубопровода, тем сильнее выражено влияние этих факторов.

Длительность реструктуризации грунта различается и проходит по-разному в зависимости от состава грунта, его состояния, сопутствующих гидрологических и геокриологических процессов, и других факторов.

В работе рассматриваются зависимости, которые можно использовать при расчете температурного режима подземного трубопровода в отсыпном грунте с изменением плотности и при переменной влажности. Учет изменения плотности грунта с разрушенной структурой производится в соответствии с ВИ 102-2-88.

В качестве примера был рассмотрен участок подземного нефтепровода, проложенного в Североевропейской части России в суглинистых грунтах. Показан процесс восстановления грунта обратной засыпки и изменение плотности и коэффициента теплопроводности при постоянной и изменяющейся влажности. Определена температура в конечном сечении нефтепровода при условии его эксплуатации при проектных параметрах вмещающего грунта, с учетом разуплотнения грунта и при изменении его влажности.

В грунтах, обладающих низкими значениями коэффициентов сцепления, трубопровод подвергается нерасчетным температурным воздействиям, приводящим конструкцию в неустойчивое состояние, с изменением положения оси трубопровода и потерей устойчивости. Поэтому расчет теплообмена трубопровода с окружающей средой, с учетом изменения свойств вмещающего грунта, является необходимым на этапе проектирования.

In the course of underground pipeline laying in abnormal conditions the compacted soil is inevitable disturbed, which leads to alteration of its physical and thermal parameters. As a result, pipeline factual operation modes will not correspond to design ones.

At the design stage of pipeline it is important to correctly determine expected value of thermal conductivity of soil. Thermal and physical parameters of backfill soil not only differ from initial ones, but also alter during pipeline operation. Change of surrounding soil humidity also affects the heat exchange of «pipeline - soil» system. The closer the pipeline zone is to the northern regions, the stronger is influence of these factors.

Soil restructuring lasting differs and proceeds depending on its constitution, condition, associated hydrological and geocryological processes, etc.

In this paper, we consider the dependencies that can be used in calculating the temperature state of underground pipelinein backfill soil with adjusting density and varying humidity. Density of disturbed soil is adjusted according to Temporary Instructions 1022-88 (VI 102-2-88).

As an example, a section of an underground oil pipeline laid in the North European part of Russia in loamy soils was considered. The process of backfill soil restoring and change of density and thermal conductivity under constant and varying humidity are shown. The temperature in the final section of the pipeline is determined under the condition of its surrounding soil operation and design parameters, taking into account the soil decompaction and humidity change.

In soils with low values of adhesion coefficients, the pipeline is subjected to uncalculated thermal effects, which leads to an unstable state of construction, with a change in the pipeline axis position and loss of stability. Therefore, the heat exchange calculation of the pipeline with the environment, changes in the properties of the surrounding soil taken into account, is necessary at the design stage.
Гаррис Н. А., Хузина А. Ф., Русаков А. И.

Уфимский государственный нефтяной технический университет,

г. Уфа, Российская Федерация

N. A. Garris, A. F. Khuzina, A. I. Rusakov

Ufa State Petroleum Technological University,

Ufa, Russian Federation e-mail: fgenerator@mail.ru

Ключевые слова: грунт обратной засыпки, реструктуризация грунтов, температурный режим нефтепровода, коэффициент теплопроводности грунта, гидрогеологические процессы, подземный трубопровод.

Key words:

backfill soil, soil restructuring, pipeline temperature state, thermal conductivity of soil, hydrological processes, underground pipeline.
С продвижением центров добычи углеводородов в удаленные и труднодоступные регионы Севера, Восточной Сибири и Дальнего Востока транспортные линии вынужденно прокладыва- ются в осложненных условиях: в мерзлоте, в слабонесущих и пучинистых грунтах, скальных породах и т.д. В результате техногенного воздействия в полосе отчуждения неизбежно механиче- 
ское разрушение сложенного различными породами и уплотненного во времени массива грунта, вмещающего трубопровод, что приводит к изменению структуры, механических и теплофизических свойств грунта. Это значит, что фактические режимы работы и состояние трубопровода будут отличаться от проектных. Этому свидетельствуют многочисленные факты [1-4].

В настоящее время при сооружении магистральных трубопроводов подземная схема укладки является наиболее распространенной. Эксплуатационные режимы в силу климатических условий и тепловой инерционности системы «труба-грунт» - неизотермические. Поэтому учет изменения теплопроводности отсыпного грунта (грунта обратной засыпки) в теплогидравлических расчетах при проектировании трубопроводов необходим. Это позволит решать актуальные задачи по уменьшению энергозатрат на перекачку, стабилизации температурного режима трубопровода, обеспечению проектного положения оси трубопровода и др.

Значимым моментом в проектировании трубопроводов является правильное определение расчетного значения коэффициента теплопроводности грунта. Одним из факторов изменения теплового режима нефтепровода является разуплотнение грунта обратной засыпки во времени. Для обратной засыпки и балластировки подземных трубопроводов в основном применяют отсыпной природный грунт, но в проектных расчетах обычно используют теплофизические характеристики грунтов без учета изменений, вызванных нарушением естественного состояния. Грунты обратной засыпки характеризуются неоднородным составом, наличием микропор и пустот. Их теплофизические и механические свойства изменяются и отличаются от первоначальных. Отличие может быть весьма существенным, если строительство нефтепровода ведется в зимний период, и грунт обратной засыпки содержит ледяные включения. Эти изменения грунтов обратной засыпки во времени выражаются, прежде всего, в самоуплотнении и самоупрочнении.

Восстановление свойств грунта происходит медленно. При тепловом воздействии вмещающий грунт подвергается протаиванию и промерзанию. Влияют также климатический и погодный факторы. В осложненных условиях эксплуатации увеличивается вероятность потери устойчивости и порыва трубопровода.
Во временной инструкции ВИ 102-2-88 [5] приводится инженерно-геологическая оценка грунтов, служащих для обратной засыпки траншей и балластировки трубопроводов. Определены коэффициенты разуплотнения $K_{p}$ и интенсивности процесса самоуплотнения $n$ отсыпных грунтов.

Для прогнозирования технического состояния неизотермического трубопровода, взаимодействующего со слабонесущими грунтами, этого недостаточно. Для расчета температурных режимов трубопроводов, особенно в сезоннопромерзающих и сезоннопротаивающих грунтах, необходимо знать, как меняется величина коэффициента теплопроводности грунта обратной засыпки.

В результате исследования свойств грунтов обратной засыпки газопровода Надым-Пунга (ПНИИИС, 1980-1984 гг.) была получена формула для определения плотности разуплотненного грунта на любой момент времени в процессе самоуплотнения

$$
\rho_{\tau}=\rho_{0}+\left(\rho-\rho_{0}\right)\left(1-e^{-n \tau}\right),
$$

где $\rho_{\tau}$ - плотность грунта соответственно на момент времени $\tau$ после отсыпки грунта;

$\rho_{0}$ - плотность грунта в момент времени $\tau=0$, т. е. сразу после экскавации грунта;

$\rho$ - плотность грунта при природном залегании;

$n$ - коэффициент, зависящий от свойств данного литологического типа грунта и характеризующий интенсивность самоуплотнения.

С учетом коэффициента $K_{p}$, характеризующего изменение плотности в первоначальный момент времени после экскавации

$$
K_{p}=\frac{\rho}{\rho_{0}},
$$

возможно при известных коэффициентах и экспериментальных значениях плотности рассчитать плотность грунта на любой момент времени после засыпки его в траншею при помощи уравнения

$$
\rho_{\tau}=\frac{\rho}{K_{p}}+\rho\left(1-\frac{1}{K_{p}}\right)\left(1-e^{-n \tau}\right),
$$

Коэффициенты разуплотнения $K_{p}$ и интенсивности самоуплотнения $n$ следует принимать по таблице 1 [1].

Формула (3) адекватно описывает процесс восстановления грунта. Из (3) видно, что плотность грунта восстанавливается по экспоненциальной зависимости: при $\tau \rightarrow \infty$, грунт стремится к своему естественному состоянию, $\rho_{\tau} \rightarrow \rho$.

\begin{tabular}{|c|c|c|c|}
\hline Наименование грунта & Состояние грунта & Коэффициент разуплотнения $K_{p}$ & \begin{tabular}{|c|} 
Коэффициент интенсивности само- \\
уплотнения $n, 1 /$ год
\end{tabular} \\
\hline $\begin{array}{l}\text { Пески мелкие и пыле- } \\
\text { ватые }\end{array}$ & $\begin{array}{c}\text { Влажные и маловлажные } \\
\text { Водонасыщенные }\end{array}$ & $\begin{array}{c}1,11-1,20 \\
1,30\end{array}$ & $\begin{array}{c}0,05-0,12 \\
0,28\end{array}$ \\
\hline Супеси & Твердые, реже пластичные & $\begin{array}{c}1,20-1,22 \\
1,28\end{array}$ & $\begin{array}{c}0,08-0,12 \\
0,24\end{array}$ \\
\hline Суглинки & Мягко- и тугопластичные & 1,24 & 0,11 \\
\hline
\end{tabular}

Таблица 1.

Коэффициенты, характеризующие изменения плотности грунтов обратных засыпок трубопроводов 
Процесс реструктуризации грунтов длительный. В обычных условиях песчаные грунты уплотняются в течение 1,5-3 лет. Однако на заболоченных и пойменных участках мерзлых торфяников, которые «при перекачке газа с положительной температурой превращаются в непроходимые болота» [1], засыпки трубопроводов из песка стабилизируются в течение $6-7$ лет после отсыпки.

Ежегодно грунт, вмещающий трубопровод, промерзает и оттаивает, а влажность грунта меняется вплоть до полного насыщения талыми и паводковыми водами. Изменяются все его характеристики. Это особенно выражено в условиях зимнего строительства, когда уплотнение грунта практически невозможно, т.к. ледяные включения отсыпного грунта не позволяют уплотнить грунт до исходного естественного состояния.

Особого рассмотрения требуют вопросы теплообмена трубопроводов, прокладываемых в сезоннооттаивающих грунтах.

В слабонесущих и пучинистых грунтах происходит изменение положения оси трубопровода относительно первоначального положения. Вместе с осадкой грунта происходит просадка трубопровода. Изменяются глубина заложения оси трубопровода, свойства вмещающих грунтов и, как следствие, условия теплообмена.

Так как эти процессы происходят при изменении температур, очевидна необходимость учета гидрологических и геокриологических процессов, приводящих к изменению механических и теплофизических свойств грунтов.

Грамотный расчет теплового взаимодействия трубопровода с окружающей средой на этапе проектирования позволяет принимать верные технические решения и значительно уменьшить риски, связанные с потерей устойчивости трубопровода.

Для прогнозирования состояния трубопровода необходимо учитывать разуплотненность грунтов, наиболее сильно выраженную в начальный период эксплуатации трубопровода. Наибольшему влиянию разуплотненности подвержены трубопроводы, пролегающие в районах Севера, тундре, заболоченной местности, водонасыщенных грунтах и др.

Расчет температурного режима таких трубопроводов значительно усложняется не только из-за нестабильности геометрических параметров проложенного трубопровода, но и вследствие изменения теплофизических свойств грунта, вмещающего трубопровод, особенно в периоды обводнения грунтов, заполнения траншей водой и т. д.
Рассчитать коэффициент теплопроводности грунта $\lambda$ на основании п. Б.7 СНиП 2.02.04-88 [6] в зависимости от влажности $\underline{w}$, плотности $\rho$, температуры $t$ не представляется возможным. Это объясняется тем, что для его определения необходимо знать не только теплоемкость $c$, но и температуропроводность грунта $a$. Коэффициент теплопроводности грунта $\lambda$ можно определить расчетным путем на основании работ [3, 7-9].

Рассмотрим один из возможных вариантов определения коэффициента теплопроводности грунта с разрушенной структурой.

Ранее [7], при исследовании теплопроводности суглинистых грунтов вдоль трассы нефтепровода Гурьев - Куйбышев (Атырау - Самара) была получена формула (4), которую можно использовать для определения коэффициента теплопроводности грунта $\lambda_{\tau}, \mathrm{BT} /\left(\mathrm{M}^{\circ} \mathrm{C}\right)$, на любой момент времени в зависимости от его плотности $\rho_{\tau}\left(\kappa г / \mathrm{M}^{3}\right)$ и влажности $w(\%)$

$$
\lambda_{\tau}=C_{1}+C_{2} \rho_{\tau} w+C_{3} \rho_{\tau} .
$$

Так, для глинистых грунтов, с предельной относительной погрешностью 5 \%, коэффициент теплопроводности $\lambda_{\tau}$ можно определить по (5).

$$
\lambda_{\tau}=-0,227+1,7 \cdot 10{ }^{5} \rho_{\tau} w+4,77 \cdot 10{ }^{4} \rho_{\tau}
$$

На основании работ А. Ф. Чудновского [8] были также получены коэффициенты $C_{1}, C_{2}, C_{3}$ для суглинистых и супесчаных грунтов [7], таблица 2.

Характер и интенсивность изменения теплофизических характеристик грунтов обратной засыпки во времени зависят от вида грунта, его свойств в естественном залегании, способов разработки и засыпки траншеи, рельефа, уровня грунтовых вод.

Рассмотрим влияние разуплотнения насыпных грунтов и длительности процесса их восстановления на тепловой режим магистрального нефтепровода. Зная плотность грунта при естественном сложении $\rho$ и после отсыпки $\rho_{0}$, можно определить плотность грунта на любой момент времени в интервале $0 . . \tau \tau$ по формулам $(1-3)$.

С изменением плотности меняется и способность грунта проводить тепло. Это значительно влияет на полный коэффициент теплопередачи $k$. По (4) определим теплопроводность грунта в момент времени $\tau=0$, т. е. сразу после экскавации и через время $\tau$. Как видно, в момент пуска трубопровода коэффициент теплопроводности имеет минимальное значение, что значительно влияет на технологию пусковых операций. В начале эксплуатации трубопровода также получаем заниженный коэффициент теплопроводности грунта.

Таблица 2.

Коэффициенты $C_{P}, C_{2}, C_{3}$ для суглинистых и супесчаных грунтов

\begin{tabular}{l|c|c|c}
\hline Тип грунта & $\mathrm{C}_{1}$ & $\mathrm{C}_{2} \cdot 10^{5}$ & $\mathrm{C}_{3} \cdot 10^{4}$ \\
\hline Слабоподзолистая тяжелосуглинистая почва пылеватая на моренных суглинках & $-0,966$ & 3,12 & 11,4 \\
\hline Дерново-подзолистая тяжелосуглинистая почва, окультуренная на моренной глине & 0,216 & 1,98 & 2,27 \\
\hline Дерново-подзолистая тяжелосуглинистая почва под лесом & 0,0454 & 3,90 & 1,14 \\
\hline Дерново-глееватая подзолистая супесчаная почва на песках & 0,159 & 0,284 & 2,27 \\
\hline
\end{tabular}

Транспорт, хранение нефти и газа | 2017, т. 15, № 4 


\section{НЕФТЕГАЗОВОЕ ДЕЛО}

Пропорционально снижению теплопроводности грунта происходит уменьшение и коэффициента теплопередачи $k$. Для подземных трубопроводов без специальной тепловой изоляции при турбулентном режиме перекачки коэффициент теплопередачи $k$ от нефти в окружающую среду практически пропорционален теплопроводности грунта, окружающего трубопровод [10]

$$
k \approx \alpha_{2}=\frac{2 \lambda_{z p}}{d \cdot \ln \frac{4 h_{0}}{d}},
$$

где $\alpha_{2}$ - внешний коэффициент теплоотдачи;

$\lambda_{\text {гр }}$ - коэффициент теплопроводности грунта;

$d$ - внутренний диаметр трубопровода;

$h_{0}$ - глубина заложения трубопровода до оси.

Зная коэффициент теплопередачи $k$, можно рассчитать температурный режим трубопровода и оценить отличие его эксплуатационных режимов от проектного.

Температура нефти $t$ на расстоянии $x$ от начала нефтепровода определяется по формуле В. Г. Шухова

$$
t=t_{0 H}+\left(t_{0}-t\right) e^{-\frac{k \pi d x}{G c_{p}}},
$$

где $t_{\mu^{\prime}}, t_{0}$ - температура нефти в начальном сечении трубопровода и температура грунта на глубине заложения оси трубопровода в ненарушенном тепловом состоянии;

$G$ и $c_{p}$ - соответственно массовый расход и теплоемкость нефти.

Определяя последовательно плотность, коэффициент теплопроводности грунта с учетом разуплотнения и коэффициент теплопередачи по приведенным формулам (1-6), рассчитаем температуру нефтепровода по (7) на различные моменты времени $\tau$ его эксплуатации. Сопоставление полученных результатов с проектными величинами позволит оценить влияние разуплотнения грунта при строительстве на температурные режимы нефтепровода при пуске и последующей его эксплуатации.

Для примера рассмотрим участок нефтепровода, проложенный в Североевропейской части России, протяженностью 200 км, диаметром $720 \times 8$ мм, с производительностью $Q=3500 \mathrm{~m}^{3} /$ ч, с начальной температурой перекачки нефти $t_{H}=40{ }^{\circ} \mathrm{C}$, плотностью нефти $\rho_{H}=862$ кг $/ \mathrm{M}^{3}$ и теплоемкостью $c_{p}=1947$ Дж/(кг·К). Температура грунта на глубине заложения оси трубопровода $h_{0}=1,16 \mathrm{M}$, в ненарушенном тепловом состоянии составляет $t_{0}=2{ }^{\circ} \mathrm{C}$. Вдоль трассы нефтепровода грунты суглинистые, плотностью при природном залегании $\rho=1760 \kappa г / \mathrm{M}^{3}$ и с суммарной влажностью $w=20 \%$. После отсыпки плотность грунта составляет $\rho_{0}=1400 \kappa г / \mathrm{M}^{3}$.

Для определения коэффициента теплопроводности расчетным путем по формуле (4) используем коэффициенты $C_{1}, C_{2}, C_{3}$ для суглинистых грунтов (таблица 2), полученные авторами [7] на основании работ А. Ф. Чудновского.

Для дерново-подзолистой тяжелосуглинистой почвы окультуренной на моренной глине, с предельной относительной погрешностью 5 \%, коэффициент теплопроводности $\lambda$ с плотностью грунта

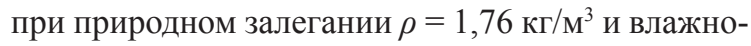
стью $w=20 \%$

$$
\lambda=0,216+1,98 \cdot 10^{-5} \cdot 1760 \cdot 20+2,27 \cdot 10^{-4} \cdot 1760=1,313 \frac{\mathrm{Bm}}{\mathcal{M} \cdot{ }^{\circ} \mathrm{C}} .
$$

При плотности грунта после отсыпки $\rho_{0}=1,4$ кг $/ \mathrm{M}^{3}$ коэффициент теплопроводности при влажности $w=20 \%$

$$
\lambda_{o}=0,216+1,98 \cdot 10^{-5} \cdot 1400 \cdot 20+2,27 \cdot 10^{-4} \cdot 1400=1,088 \frac{\mathrm{Bm}}{\mathrm{M} \cdot{ }^{\circ} \mathrm{C}} .
$$

Как отмечается в [1], плотность суглинка стабилизируется примерно через 8-12 лет, т. е. $\tau=8$ лет. По формуле (1)

$$
\rho_{\tau=8}=1400+(1760-1400)\left(1-e^{-0,11 \cdot 8}\right)=1611 \kappa 2 / \mathcal{M}^{3} .
$$

Коэффициент теплопроводности через 8 лет $\left(\rho_{\tau}=1611 \mathrm{\kappa} \Gamma / \mathrm{M}^{3} ; w=20 \%\right)$

$$
\lambda_{\tau=8}=0,216+1,98 \cdot 10^{-5} \cdot 1610 \cdot 20+2,27 \cdot 10^{-4} \cdot 1611=1,220 \frac{\mathrm{Bm}}{\mathrm{M} \cdot{ }^{\circ} \mathrm{C}} .
$$

Графическая зависимость плотности и теплопроводности суглинков от времени иллюстрируется рисунком 1.

Анализируя полученные результаты, можно отметить, что полного восстановления свойств грунта даже за такой длительный период не происходит. Через 8 лет после отсыпки грунта прогнозируется увеличение теплопроводности на $12 \%$.

Значительно большее влияние на способность грунта с нарушенной структурой проводить тепло оказывает его увлажнение. Вдоль трассы нефтепровода влажность меняется, местами возможны обводненные участки. Очевидна также зависимость от климата и сезонности: влажность грунта изменяется в зависимости от времени года, например, весной грунт насыщается талыми водами и имеет наибольшую влажность, лето возможно засушливое или дождливое и т. д. Увеличение влажности за счет таяния льда также приводит к увлажнению грунта и увеличению теплоотдачи.

В таблице 3 представлены результаты расчета изменения плотности $\rho_{\tau}$ и коэффициента теплопроводности грунта $\lambda_{\tau}$ по формулам (1) и (4) в процессе уплотнения для диапазона влажностей от 20 до 40 \%. Так, с учетом не только разуплотнения, но и насыщения грунта влагой, при изменении влажности от 20 до $35 \%$, коэффициент теплопроводности меняется в 1,4 раза, относительное изменение теплопроводности грунта обратной засыпки может составить до $28 \%$ :

$$
\Delta=\frac{\rho_{\omega=35}-\rho_{\omega=20}}{\rho_{\omega=35}} \cdot 100 \%=\frac{1,7-1,23}{1,7} \cdot 100 \%=28 \% .
$$

Увеличение коэффициента теплопередачи пропорционально увеличению теплопроводности и также составляет $28 \%$. 


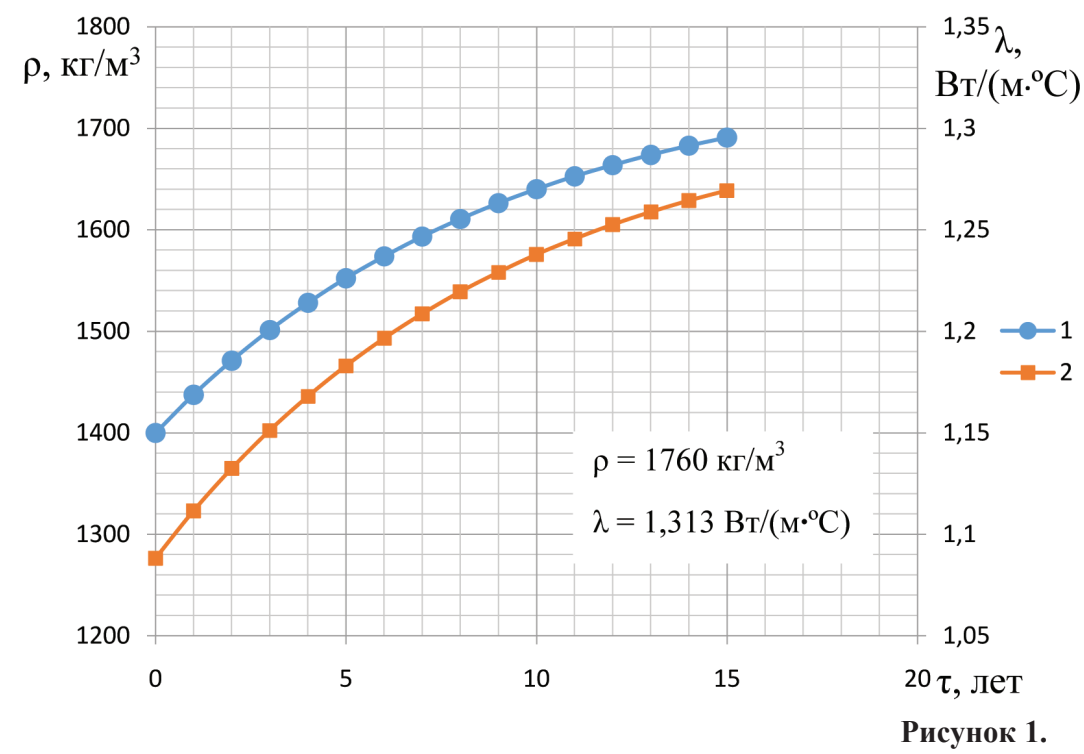

Изменение плотности (1) и коэффициента теплопроводности (2) отсыпного грунта во времени при постоянной влажности $w=20 \%$

Таблица 3.

Изменение плотности и теплопроводности грунта нарушенной структуры в процессе восстановления

\begin{tabular}{l|c|c|c|c|c|c}
\hline$\tau$, & \multirow{2}{*}{$\begin{array}{c}\rho_{\tau}, \\
\text { год }\end{array}$} & \multicolumn{5}{|c}{$\lambda_{\tau}, \mathrm{BT} /\left(\mathrm{M} \cdot{ }^{\circ} \mathrm{C}\right)$} \\
\hline 0 & 1400 & 1,09 & 1,23 & 1,37 & 1,50 & 1,64 \\
\hline 2 & 1471 & 1,13 & 1,28 & 1,42 & 1,57 & 1,71 \\
\hline 4 & 1528 & 1,17 & 1,32 & 1,47 & 1,62 & 1,77 \\
\hline 6 & 1574 & 1,20 & 1,35 & 1,51 & 1,66 & 1,82 \\
\hline 8 & 1611 & 1,22 & 1,38 & 1,54 & 1,70 & 1,86 \\
\hline
\end{tabular}

В результате расчета коэффициента теплопередачи по (6), находятся значения $k_{w=35}=2,56 \mathrm{BT} /\left(\mathrm{M}^{\circ}{ }^{\circ} \mathrm{C}\right)$ и $k_{w=20}=1,84 \mathrm{BT} /\left(\mathrm{M}^{\circ} \mathrm{C}\right)$.

$\mathrm{B}$ проектном режиме (без учета разуплотнения грунта) температура в конечном сечении нефтепровода, $\mathrm{x}=200000$ м, определяется на основании (7)

$$
t_{\kappa}=2+(40-2) \cdot e^{-\frac{1,98 \cdot 3,14 \cdot 0,704 \cdot 2 \cdot 10^{5}}{3500 \cdot 862 \cdot 1947}}=24,2^{\circ} \mathrm{C} .
$$

Аналогичные расчеты проводятся для разуплотненного грунта при влажности $w=20 \%$ и $w=35 \%$. Результаты расчетов представлены в таблице 4.

Расчеты показывают, что даже после 8-ми лет эксплуатации температура нефтепровода в конечном сечении может существенно отличаться от проектной за счет нарушения структуры грунта и изменения водного режима грунтов обратной засыпки. При этом теплопотери, определяемые падением температуры по длине трубопровода, могут как уменьшаться, так и увеличиваться. Себестоимость перекачки нефти при этом изменяется практически пропорционально. Для снижения транспортных расходов требуются специальные технические решения.
Таблица 4.

Изменение температурного режима нефтепровода

\begin{tabular}{|c|c|c|c|}
\hline \multirow{2}{*}{$\begin{array}{l}\text { Расстоя- } \\
\text { ние от } \\
\text { НПС, } \\
x, \text { км }\end{array}$} & \multirow{2}{*}{$\begin{array}{c}\text { Температура, } \\
{ }^{\circ} \mathrm{C} \text {, без учета } \\
\text { разуплотнения } \\
\text { грунта, } w=20 \% \\
\end{array}$} & \multicolumn{2}{|c|}{$\begin{array}{c}\text { Температура, }{ }^{\circ} \mathrm{C}, \text { с учетом } \\
\text { восстановления свойств грунта } \\
\text { обратной засыпки, } \tau=8 \text { лет } \\
\end{array}$} \\
\hline & & $w=20 \%$ & $w=35 \%$ \\
\hline 0 & 40,0 & 40,0 & 40,0 \\
\hline 100 & 31,1 & 31,6 & 28,9 \\
\hline 200 & 24,2 & 25,1 & 21,0 \\
\hline
\end{tabular}

Как видно, самоуплотнение насыпных грунтов до стабилизированных значений происходит в течение длительного времени. В настоящее время практикуется искусственное (техническое) уплотнение грунтов в траншее сразу после их засыпки, что повышает надежность закрепления трубопроводов минеральным грунтом. Но стоит отметить, что такая технология эффективна только в случае полутвердой и тугопластичной консистенции отсыпных грунтов. В грунтах, обладающих низкими значениями коэффициентов сцепления, трубопровод подвергается нерасчетным температурным воздействиям, приводящим конструкцию в неустойчивое состояние, с изменением положения оси трубопровода и потерей устойчивости.

\section{Выводы}

1. Расчет теплообмена трубопровода с окружающей средой с учетом изменения свойств вмещающего грунта является необходимым на этапе проектирования. Это позволит сократить многочисленные аварийные ситуации, связанные с тепловым взаимодействием системы «труба-грунт».

2. Аналогичные исследования необходимы для трубопроводов, сооружаемых в зимнее время, разуплотненный грунт которых содержит большой объем ледяных включений. 


\section{СПИСОК ИСПОЛЬЗУЕМЫХ ИСТОЧНИКОВ}

1 Изменение балластирующей способности грунтов обратной засыпки во времени / Н. П. Васильев, Ю. А. Коржевский, И. Г. Коробанова и др.// Транспорт и хранение нефти и нефтепродуктов. М.: ВНИИОЭНГ, 1985. № 12. C. 42-44.

2 Гаррис Н. А., Закирова Э. А. Третий принцип использования мерзлых грунтов в качестве основания трубопроводов // Территория Нефтегаз. 2017. № 3. C. $100-108$.

3 Гаррис Н. А. Эксплуатация нефтепродуктопроводов в различных температурных режимах и загрузках при условии сохранности экологической среды: автореф. дис. ... д-ра техн. наук. Уфа, 1998. 48 с.

4 Харионовский В. В. Надежность и ресурс конструкций газопроводов. М.: Недра. 2001. 467 с.

5 ВИ 102-2-88 Временная инструкция «Учет удерживающей способности грунтов нарушенной структуры при прокладке стальных трубопроводов на обводненных участках». ВНИИСТ, ЮЖНИИГИПРОГАЗ, ГИПРОТЮМЕНЬНЕФТЕГАЗ. УТВ. 10.02.1988.URL: http://meganorm.ru/Index2/1/ 4293832/4293832127.htm (Дата обращения 07.09.2017).

6 СП 25.13330.2012 Основания и фундаменты на вечномерзлых грунтах. Актуализированная редакция СНиП 2.02.04-88. М.: Минрегион России. 2012. 123 с.

7 Тугунов П. И., Гаррис Н. А., Гималетдинов Г. М. К определению эффективного значения коэффициента теплопроводности грунта // Транспорт и хранение нефти и нефтепродуктов. М.: ВНИИОЭНГ. 1980. № 8. C. $2-3$.

8 Чудновский А. Ф. Теплофизические характеристики дисперсных материалов. М.: Физматгиз, 1962. $456 \mathrm{c}$.

9 Инженерная геокриология: справочное пособие / Э. Д. Ершов, Л. Н. Хрусталев, Г. И. Дубиков, С. Ю. Пармузин; под ред. Э.Д. Ершова. М.: Недра, 1991. 439 с.

10 Тугунов П. И. Нестационарные режимы перекачки нефтей и нефтепродуктов. М.: Недра, 1984. 224 с.

\section{REFERENCES}

1 Vasilev N. P., Korzhevsky Yu. A., Korabanova I. G. etc. Change of backfill soil ballasting capacity in time. Transport $i$ hranenie nefti i nefteproduktov - Transportation and storage of oil and petroleum products. Moscow, VNIIOENG Publ., 1985, vol.12, pp. 42-44. [in Russian].

2 Garris N. A., Zakirova E. A. The third principle of using frozen soils as the pipelines foundation. Territorija neftegaz - Oil and gas territory, 2017, no. 3, pp. 100-108. [in Russian].

3 Garris N. A. Ekspluataciya nefteproduktoprovodov $v$ razlichny temperaturnyh rezhimah i zagruzkah pri uslovii sohrannosti ekologicheskoi sredy: avtoref. dic. ... d-ra tehn. nauk. [Operating of oil-products pipelines in different charging and temperature conditions considering the requirements of environmental integrity. Abstract of the Dr. of tech. sci. diss.] Ufa, 1998. 48 p. [in Russian].
4 Kharionovsky V. V. Nadezhnost' i resurs konstrukcij gazoprovodov. [Reliability and margin of safety of gas pipeline constructions]. Moscow, Nedra Publ., 2001. 467 p. [in Russian].

5 TI 102-2-88. Allowance for the retention capacity of disturbed structure soils during the laying of steel pipelines in watered areas (Temporary instruction). VNIIST, YUZHNIIGIPROGAZ, GIPROTYUMENNEFTEGAZ. Approved 02.10.1988. Available at: http://meganorm.ru/ Index $2 / 1 / 4293832 / 4293832127 . h t m$ (accessed date: 07.09.2017). [in Russian].

6 SP 25.13330.2012. Rafts and foundations on permafrost. Revised edition SNiP (Construction norms \& regulations) 2.02.04-88. Moscow, Regional development ministry of Russian Federation publ., 2012. 116 p. [in Russian].

7 Tugunov P. I., Garris N. A., Gimaletdinov G. M. Determination of the effective value of soil thermal conductivity. Transport $i$ hranenie nefti i nefteproduktovTransportation and storage of oil and petroleum products. Moscow, VNIIOENG Publ., 1980, vol. 8, pp. 2-3. [in Russian].

8 Chudnovsky A. F. Teplofizicheskie harakteristiki dispersnyh materialov [Thermophysical characteristics of disperse materials]. Moscow, Fizmatgiz Publ., 1962. 456 p. [in Russian].

9 Ershov E. D., Khrustalev L. N., Dubikov G. I., Parmusin S. Yu. Inzhenernaya geokriologiya: Spravochnoe posobie. [Engineering geocryology: A reference guide. Ed. E.D. Ershov]. Moscow, Nedra Publ., 1991. 439 p. [in Russian].

10 Tugunov P. I. Nestacionarnye rezhimy perekachki neftej $i$ nefteproduktov. [Nonsteady states of oils and petroleum products transfer]. Moscow, Nedra Publ., 1984. 224 p. [in Russian].

Гаррис Н. А., д-р техн. наук, профессор, заведующая кафедрой «Гидрогазодинамика трубопроводных систем и гидромашины» ФГБОУ ВО «УГНТУ», г. Уфа, Российская Федерачия

N. A. Garris, Doctor of Engineering Sciences, Professor, Head of the Chair «Fluid Dynamics of Pipeline Networks and Fluid Machinery» FSBEI HE «USPTU», Ufa, Russian Federation

e-mail:nina_garris@mail.ru

Хузина А. Ф., магистрант, ФГБОУ ВО «УГНТУ», 2. Уфа, Российская Федерачия

A. F. Khuzina, Master Student, FSBEI HE «USPTU», Ufa, Russian Federation

e-mail:xuzina.9696@mail.ru

Русаков А. И., аспирант кафедры «Гидрогазодинамика трубопроводных систем и гидромашины» ФГБОУ ВО «УГНТУ», г. Уфа, Российская Федераиия

A. I. Rusakov, Post-Graduate Student of the Chair «Fluid Dynamics of Pipeline Networks and Fluid Machinery» FSBEI HE «USPTU», Ufa, Russian Federation e-mail: chake100500@gmail.c 